\title{
Taschentücher einwickeln \\ Die Seite für Kinder
}

Brigitte Lutz-Westphal und Alexander Schulte

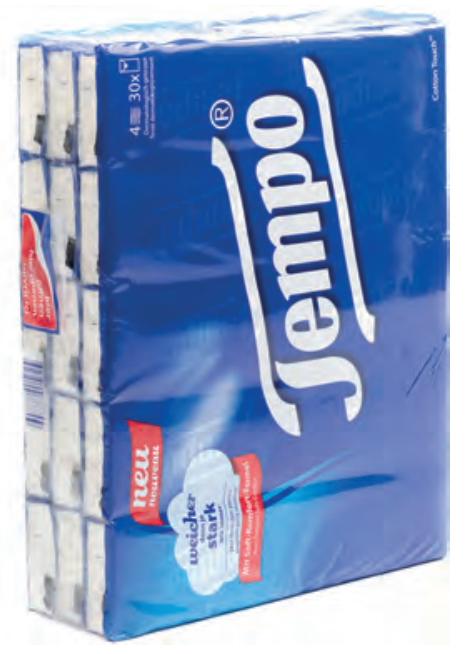

Nimm eine große Taschentuchpackung und öffne sie vorsichtig, ohne die Verpackungsfolie zu zerreißen.

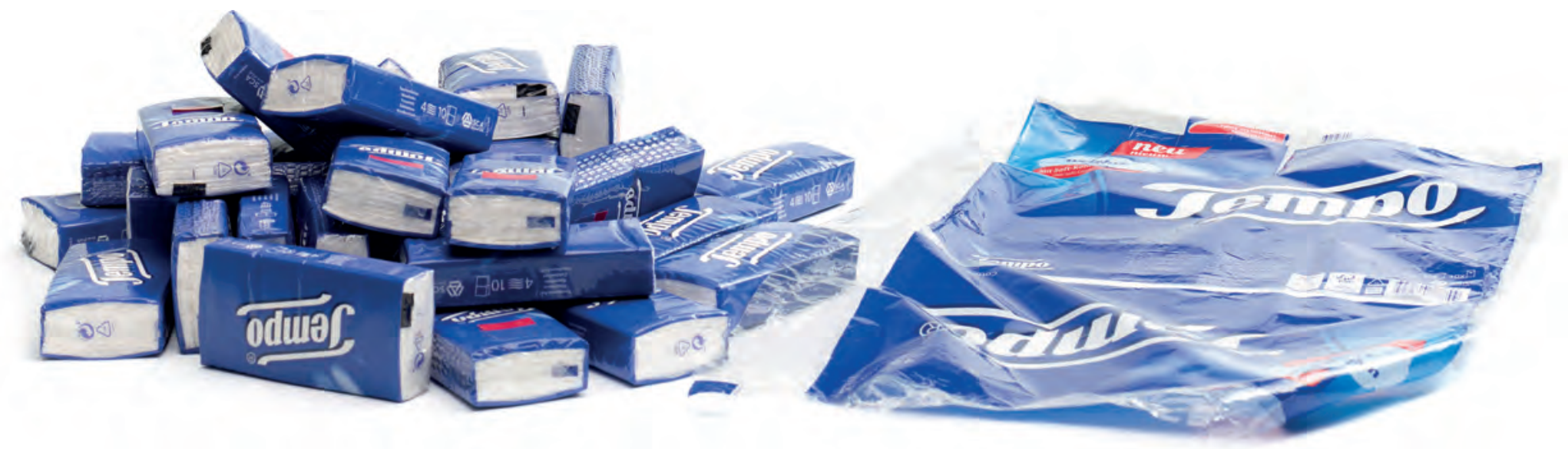


Gruppiere die Taschentuchpäckchen anders und packe sie dann mit der Folie wieder ein. Warum kann es passieren, dass die Verpackungsfolie plötzlich nicht mehr ausreicht, um alles komplett zu umhüllen? Es sind doch gleich viele Taschentuchpäckchen geblieben!

Für welche Anordnungen braucht man besonders viel Verpackung? Für welche besonders wenig? Probiere so viele verschiedene Anordnungen aus, wie dir einfallen!

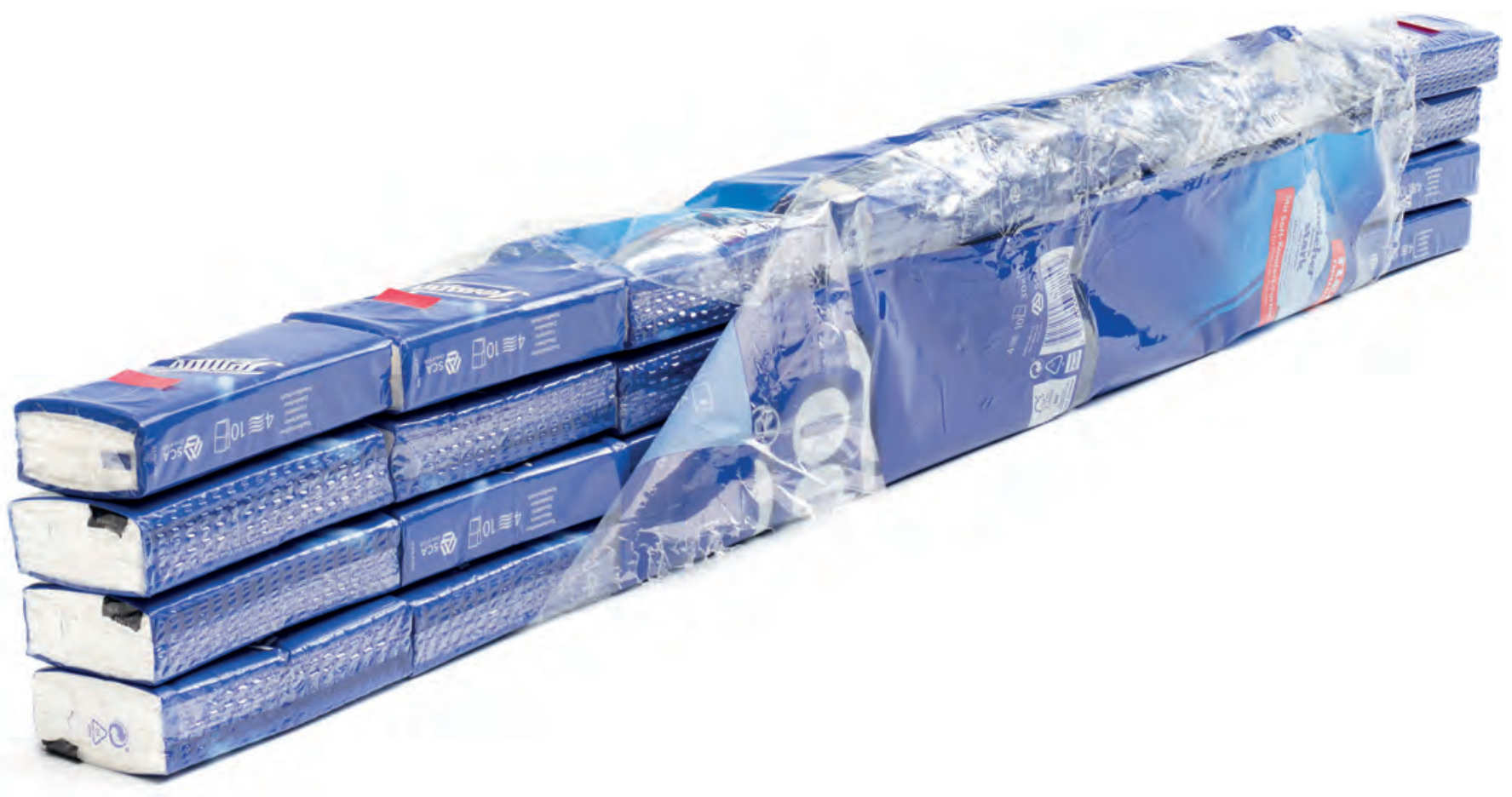

Diese Kinderseite basiert auf einer Idee, die wir auf www.4teachers.de gefunden haben ( $w w w .4$ teachers.de/?action=material\&id=30735).

Prof. Dr. Brigitte Lutz-Westphal und Alexander Schulte, Didaktik der Mathematik, Fachbereich Mathematik und Informatik,

Freie Universität Berlin, Königin-Luise-Str. 24-26, 14195 Berlin, brigitte.lutz-westphal@math.fu-berlin.de,

Freie Universitat Berlin, 